Polymer Journal, Vol. 8, No. 4, pp 325-330 (1976)

\title{
Thermal Properties of Mixture of Poly A and Poly U
}

\author{
Shigeyuki Tanaka, Yoshihiro BABA, and Akihiro Kagemoto \\ Department of General Education, Osaka Institute of Technology, \\ 5-Chome, Omiya, Asahi-ku, Osaka 535, Japan.
}

(Received November 7, 1975)

\begin{abstract}
The thermal properties of Poly $(\mathrm{A}+\mathrm{U})$ formed by an equimolar mixture of Poly $A$ and Poly $U$ in aqueous solutions of various concentrations of $\mathrm{NaCl}$ were studied calorimetrically. First, the measurements using the modified DSC were carried out and the transition enthalpy $\left(\Delta H_{\mathrm{m}}\right)$ was estimated for Poly $(\mathrm{A}+\mathrm{U})$ in the solutions of various salt concentrations. The heat of mixing of an equimolar mixture of Poly A and Poly U under the same experimental conditions as used in the DSC measurement was measured by using a LKB microcalorimeter at $298 \mathrm{~K}$; the results obtained were found to depend on salt concentration as well. The agreement between the enthalpy of formation of Poly $(\mathrm{A}+\mathrm{U})$ estimated from the microcalorimeter and the heat of transition determined by the DSC method was fairly close.
\end{abstract}

KEY WORDS DSC / Poly A / Poly U / Helix-Coil Transition /

Heat of Mixing / Poly $(\mathrm{A}+\mathrm{U})$ Complex / CD and UV Spectrum /

It is known that an equimolar mixture of poly (riboadenylic acid) (Poly A) and poly(ribouridylic acid) (Poly $U$ ) forms well-defined Poly $(A+U)$ complexes between different chains. The structure of such a complex is a double-stranded helix much like that of DNA, and the stability of its structure depends on the environmental parameters, such as the temperature and salt concentration. ${ }^{1}$

Many studies have been reported in this field since Warner ${ }^{2}$ found that an equimolar mixture of Poly $A$ and Poly $U$ forms the complex of Poly $(\mathrm{A}+\mathrm{U})$ with a double stranded helical structure. But almost all studies have been carried out by the optical method.

In this paper, in order to obtain the thermal information about the complex formed between Poly $\mathrm{A}$ and Poly $\mathrm{U}$ in the aqueous solutions of various concentrations of $\mathrm{NaCl}$, we carried out the thermal analysis of Poly $(\mathrm{A}+\mathrm{U})$ in the solutions of various salt concentrations at $\mathrm{pH}$ 7.60 and 7.21 by using a modified differential scanning calorimeter (DSC). We also measured the heats of mixing of an equimolar mixture of Poly A and Poly U solutions under the same experimental conditions as used in the DSC method. The agreement between the enthalpy of formation of an equimolar mixture of Poly A and Poly $U$ estimated from a microcalorimeter and the heat of transition of $\operatorname{Poly}(\mathrm{A}+\mathrm{U})$ complex found by the DSC method was fairly close.

\section{EXPERIMENTAL}

\section{Material}

The poly(riboadenylic acid) (Poly A) and polyribouridylic acid (Poly $U$ ) used in this study were purchased from Miles Laboratories Inc. and were used without further purification. All other materials were commercial products of analytical reagent grade.

For the DSC measurement, Poly A and Poly U samples were dissolved in a buffer solution with different concentrations of $\mathrm{NaCl}$, and Poly $\mathrm{A}$ and Poly $U$ solutions were mixed in the ratio of $1: 1$; then this solution was allowed to stand overnight at about $278 \mathrm{~K}$. The concentrations of Poly A and Poly $U$ were about $0.2 \%$, as determined by the measurement of absorption spectra at 257 and $261 \mathrm{~nm}$, taking $E(P)=10400$ $9900,{ }^{3}$ respectively.

For the measurement of the heats of mixing of Poly A and Poly U solutions, the concentrations of those solutions were about one-tenth that used for the DSC measurement.

The buffer solution used in order to adjust $\mathrm{pH}$ was $0.1 M$ tris- $\mathrm{HCl}$ solution $(\mathrm{pH} 7.60$ and 7.21). 


\section{Apparatus}

The differential scanning calorimeter (DSC, Model M8005, Rigaku Denki Co. Ltd.) used in this study was modified so as to be able to measure a slight change of the heat for a small amount of sample. ${ }^{7}$ The heating rate of the DSC measurement was $10 \mathrm{~K} / \mathrm{min}$.

The calorimeter used for the heat of mixing of an equimolar mixture of Poly $A$ and Poly $U$ solutions was similar to the LKB batch-type microcalorimeter. The temperature measured was about $298 \mathrm{~K}$.

The measurement of the temperature dependence of absorbance was made by a Hitachi 124 spectrophotometer equipped with thermostated cells. The temperature in the cell was measured by means of a $\mathrm{Cu}-$ Constantan thermocouple inserted in the cell.

The circular dichroism measurement for an equimolar mixture of Poly $A$ and Poly $U$ with various salt concentrations was made using a spectropolarimeter (Japan Spectroscopic Co. Ltd., $\mathrm{J}-20$ ).

\section{RESULT AND DISCUSSION}

Helix-Coil Transition of Poly $(A+U)$

The thermal behavior of an equimolar mixture of Poly $A$ and Poly $U$ has been studied by using the modified DSC. Some typical DSC curves obtained for the solutions of various salt concentrations at $\mathrm{pH} 7.60$ are shown in Figure 1. As seen in Figure 1, the DSC curves show one peak in the solutions of $10^{-5}$ - and 0.1 -molar salt concentrations, and two peaks in the 0.5 molar salt solution. In order to confirm the one or two peaks which appeared in the DSC curves, the dependence of absorbance on the temperature under the same experimental conditions as used in the DSC measurement was studied using the spectrophotometer.

The plots of absorbance at 260- and 280-nm wavelengths against temperature are shown in Figure 2. The absorbance at $260 \mathrm{~nm}$ increases from about 310 and $325 \mathrm{~K}$ in $10^{-5}$ - and 0.1 molar salt solutions, respectively. But the absorbance at $280 \mathrm{~nm}$ is independent of temperature, implying that a triple stranded helical

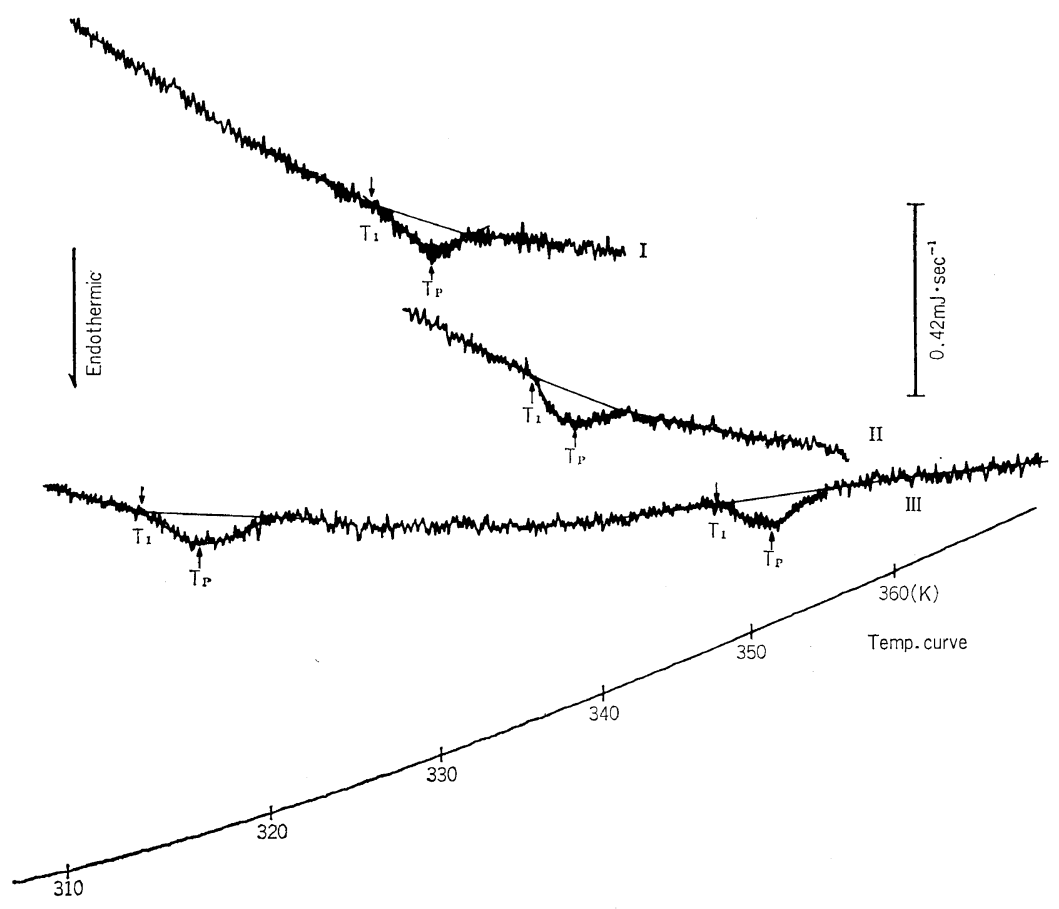

Figure 1. DSC curves of an equimolar mixture of Poly A and Poly $U$ at $\mathrm{pH} 7.60$ in various $\mathrm{NaCl}$ concentrations: I, $10^{-5}$, II, 0.1 , and III, 0.5 mole. 

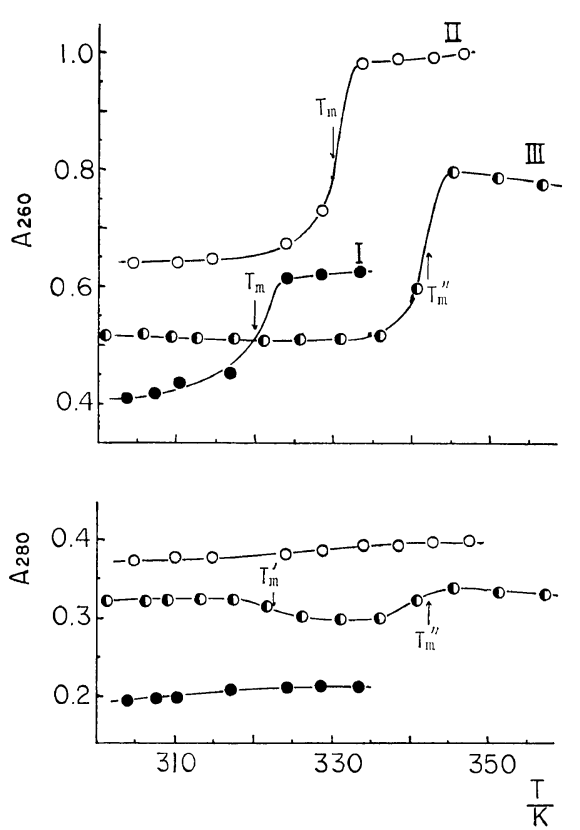

Figure 2. Dependence of absorbance $\left(\mathbf{A}_{280}, \mathbf{A}_{260}\right)$ on temperature at $\mathrm{pH} 7.60$ for an equimolar mixture of Poly $\mathrm{A}$ and Poly $\mathrm{U}$ in various $\mathrm{NaCl}$ concentrations: I, $10^{-5}, \mathrm{II}, 0.1$, and III, 0.5 mole. $T_{\mathrm{m}}$ : transition temperature of reaction $\operatorname{Poly}(\mathrm{A}+\mathrm{U}) \longrightarrow$ Poly A+Poly U; $T_{\mathrm{m}}$ ': that of reaction $\operatorname{Poly}(\mathrm{A}+\mathrm{U})$ $\longrightarrow \frac{1}{2} \operatorname{Poly}(\mathrm{A}+2 \mathrm{U})+\frac{1}{2}$ Poly A; $T_{\mathrm{m}}{ }^{\prime \prime}$ : that of reaction $\frac{1}{2}$ Poly $(A+2 U)+\frac{1}{2}$ Poly $A \longrightarrow$ Poly A + Poly U.

structure of Poly $(A+2 U)$ does not appear in the region of this salt concentration. Therefore, the temperatures of 320 and $330 \mathrm{~K}$, which are the middle points of the absorbance change at $260 \mathrm{~nm}$, may correspond to the helix - coil transition temperatures $\left(T_{\mathrm{m}}\right)$ of Poly $(\mathrm{A}+\mathrm{U})$ complex formed by an equimolar mixture of Poly $\mathrm{A}$ and Poly $U$ in solutions of $10^{-5}$ - and 0.1 -molar salt concentrations, respectively. Agreement between the temperature $\left(T_{1}\right)$ where the endothermic peak in the DSC curves begins to appear and $T_{\mathrm{m}}$ obtained from the absorbance change at $260 \mathrm{~nm}$ is fairly close within experimental error. Thus the one endothermic peak which appears in the DSC curves may be considered to correspond to the helix-coil transition of Poly $(\mathrm{A}+\mathrm{U})$ in the following reaction as the temperature is increased:

$$
\text { Poly }(\mathrm{A}+\mathrm{U}) \longrightarrow \text { Poly A+Poly U }
$$

In the 0.5 -molar salt solution, the absorbance at $260 \mathrm{~nm}$ increases from about $335 \mathrm{~K}$, and that at $280 \mathrm{~nm}$ decreases from $320 \mathrm{~K}$ and then increases from about $335 \mathrm{~K}$. This behavior may be explained as follows, according to Stevens and Felsenfeld: ${ }^{1}$

With increasing temperature Poly $(\mathrm{A}+\mathrm{U})$ at first forms the triple stranded helical structure of $\operatorname{Poly}(\mathrm{A}+2 \mathrm{U})$ at $325 \mathrm{~K}\left(T_{\mathrm{m}}{ }^{\prime}\right)$ according to reaction (2) and then the Poly $(\mathrm{A}+2 \mathrm{U})$ complex converts into Poly A and Poly U at $340^{\circ} \mathrm{K}\left(T_{\mathrm{m}}{ }^{\prime \prime}\right)$ according to reaction (3)

$$
\begin{aligned}
& \text { Poly }(\mathrm{A}+\mathrm{U}) \longrightarrow \frac{1}{2} \text { Poly }(\mathrm{A}+2 \mathrm{U})+\frac{1}{2} \text { Poly A } \\
& \frac{1}{2} \text { Poly }(\mathrm{A}+2 \mathrm{U})+\frac{1}{2} \text { Poly A } \longrightarrow \text { Poly A }+ \text { Poly U }
\end{aligned}
$$

Assuming that the peak area of the DSC curve for $\operatorname{Poly}(\mathbf{A}+\mathbf{U})$ in various salt concentrations corresponds to the heat of transition, the heat of transition per mole of base pair $\left(\Delta H_{\mathrm{m}}\right)$ is obtained; this is plotted against the salt con-
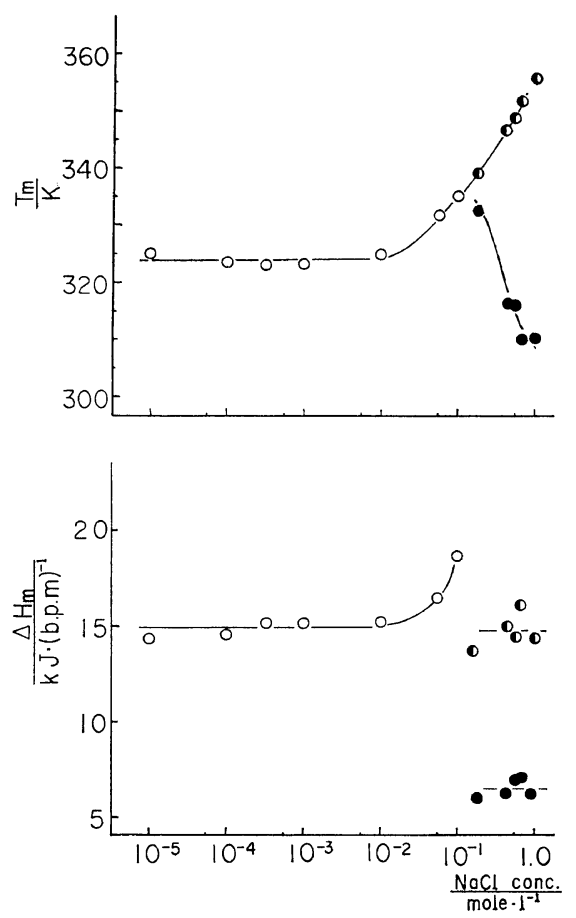

Figure 3(a). Dependence of transition temperature $\left(T_{\mathrm{m}}\right)$ and enthalpy $\left(\Delta H_{\mathrm{m}}\right)$ on concentration of $\mathrm{NaCl}$ at $\mathrm{pH} 7.60$ for various reactions: $\bigcirc$, Poly $(\mathrm{A}+\mathrm{U}) \longrightarrow$ Poly A + Poly U; O, Poly $(\mathrm{A}+\mathrm{U})$ $\longrightarrow \frac{1}{2}$ Poly $(\mathrm{A}+2 \mathrm{U})+\frac{1}{2}$ Poly $\mathrm{A}$; and $\mathbf{D}, \frac{1}{2} \operatorname{Poly}(\mathrm{A}+$ $2 \mathrm{U})+\frac{1}{2}$ Poly $\mathrm{A} \longrightarrow$ Poly A + Poly U. 
centration at $\mathrm{pH} 7.60$ and 7.21 in Figures 3(a) and (b), together with the transition temperature $T_{1}\left(=T_{\mathrm{m}}\right)$ estimated from the DSC curves.

The Dependence of $T_{\mathrm{m}}$ and $\Delta H_{\mathrm{m}}$ on salt concentration can be classified into three cases, as seen in Figure 3(a):

(a) Both $T_{\mathrm{m}}$ and $\Delta H_{\mathrm{m}}$ have a fixed value in regions of salt concentration from $10^{-5}$ to $10^{-2}$ molar, suggesting that the change may correspond to reaction (1).

(b) Upon increasing the salt concentration from $10^{-2}$ to 0.1 molar, $T_{\mathrm{m}}$ and $\Delta H_{\mathrm{m}}$ in reaction (1) increase, in comparison with the values for DNA in a previous paper. ${ }^{7}$

(c) When the salt concentration is more than 0.1 molar, $T_{\mathrm{m}}$ of reaction (2) decreases with increasing salt concentration. However, $\Delta H_{\mathrm{m}}$ has a fixed value of about $6 \mathrm{~kJ} / \mathrm{bpm}$ independent of the salt concentration. In reaction (3) $T_{\mathrm{m}}$ increases with the salt concentration, but $\Delta H_{\mathrm{m}}$ has a fixed value of about $15 \mathrm{~kJ} / \mathrm{bpm}$ independent of the salt concentration.
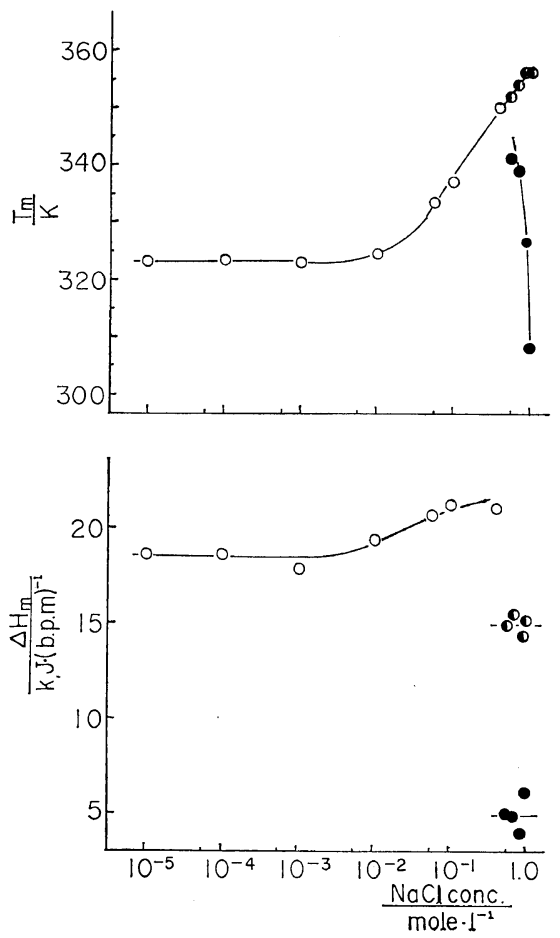

Figure 3(b). Dependence of transition temperature $\left(T_{\mathrm{m}}\right)$ and enthalpy $\left(\Delta H_{\mathrm{m}}\right)$ on concentration of $\mathrm{NaCl}$ at $\mathrm{pH} 7.21$ for various reactions: $\bigcirc$, (1) as shown in Figure 3(a).
Table I. Transition temperature $\left(T_{\mathrm{m}}\right)$ and enthalpy $\left(\Delta H_{\mathrm{m}}\right)$ of $\mathrm{Poly}(\mathrm{A}+\mathrm{U})$ in dilute $\mathrm{NaCl}$ and $0.1-M \mathrm{NaCl}$ estimated from the DSC method

\begin{tabular}{lccccc}
\hline & \multicolumn{2}{c}{ Dilute $\mathrm{NaCl}$} & & \multicolumn{2}{c}{$0.1-M \mathrm{NaCl}$} \\
\cline { 2 - 3 } \cline { 5 - 6 } $\mathrm{pH}$ & $T_{\mathrm{m}}, \mathrm{K}$ & $\begin{array}{c}\Delta H_{\mathrm{m}}, \\
\mathrm{kJ}(\mathrm{bpm})^{-1}\end{array}$ & & $T_{\mathrm{m}}, \mathrm{K}$ & $\begin{array}{c}\Delta H_{\mathrm{m}}, \\
\mathrm{kJ}(\mathrm{bpm})^{-1}\end{array}$ \\
\hline 7.60 & 324.1 & 15.0 & & 335.2 & 18.7 \\
7.21 & 323.5 & 18.6 & & 334.2 & 21.2 \\
\hline
\end{tabular}

$T_{\mathrm{m}}$ and $\Delta H_{\mathrm{m}}$ of reactions (1), (2), and (3) at pH 7.21 are shown in Figure 3(b), a similar diagram is obtained at $\mathrm{pH} 7.60$. But the salt concentration for which Poly $(\mathrm{A}+\mathrm{U})$ converts into Poly $(\mathrm{A}+2 \mathrm{U})$ at $\mathrm{pH} 7.21$ is higher than that at $\mathrm{pH}$ 7.60. The results obtained for reaction (1) in various salt concentrations are listed in Table I.

As seen in Table I, it appears that the heats of helix-coil transitions of the Poly $(\mathrm{A}+\mathrm{U})$ complex in the solutions with a dilute and 0.1-molar salt concentrations depend roughly on $\mathrm{pH}$.

The Heats of Mixing of Poly $A$ and Poly $U$

In order to obtain further information about the dependence of $\Delta H_{\mathrm{m}}$ on salt concentration, the heats of mixing of an equimolar mixture of Poly A and Poly U (Poly A+Poly U) under the same experimental conditions as used in the DSC measurement have been measured by using a LKB batch microcalorimeter at $298 \mathrm{~K}$.

The results obtained are exothermic; the plots of the heat of mixing per mole of base pair $\left(\Delta H^{\mathrm{M}}\right)$ against the salt concentration are shown in Figure 4. The dependence of $\Delta H^{\mathrm{M}}$ on salt concentration seems to be classifiable into two cases:

(a) $\Delta H^{\mathrm{M}}$ of (Poly $\mathrm{A}+$ Poly $\mathrm{U}$ ) seems to give a fixed value independent of salt concentration in each $\mathrm{pH}$ when the salt concentration is less than $10^{-2}$ molar. Assuming that the heat of dilution in this system is very small and can be neglected, the enthalpy of the complex formation of $1: 1$ of Poly $\mathrm{A}$ and Poly $\mathrm{U}$ in the infinite dilution of the salt is estimated to be approximately $-15.5 \mathrm{~kJ} / \mathrm{bpm}$ at $\mathrm{pH} 7.60$ and -18.1 $\mathrm{kJ} / \mathrm{bpm}$ at $\mathrm{pH} 7.21$, respectively. The effect of the change in $\mathrm{pH}$ on the enthalpy of the $1: 1$ complex formation of Poly $A$ and Poly $U$ is about $-2.6 \mathrm{~kJ} / \mathrm{bpm}$. The value obtained is in 


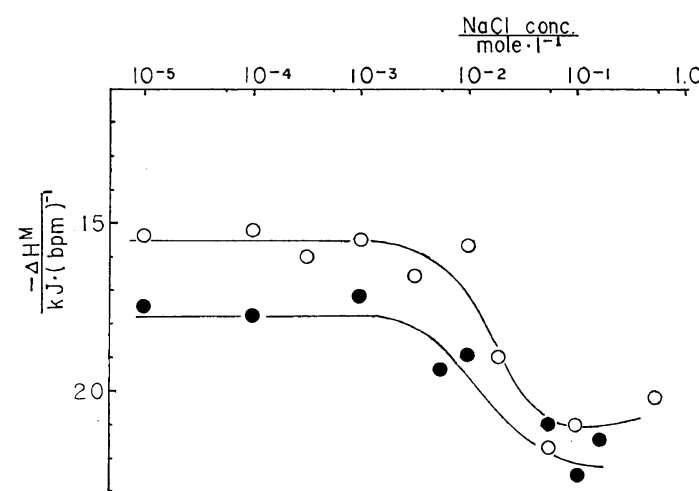

Figure 4. Dependence of heats of mixing on concentration of $\mathrm{NaCl}$ for Poly $\mathrm{A}$ : Poly $\mathrm{U}=1: 1 \mathrm{mix}-$ ture at $\mathrm{pH} 7.60, \mathrm{O}$, and 7.21,

close agreement with that estimated by the DSC measurement.

(b) $\Delta H^{\mathrm{M}}$ seems to increase in absolute value when the salt concentration is more than $10^{-2}$ molar. A drastic change in the formation of the $1: 1$ complex which is formed by mixing Poly $\mathrm{A}$ and Poly $\mathrm{U}$ may be brought about near this salt concentration, implying that such an increase of $\Delta H^{\mathrm{M}}$ is the amount necessary to convert a $1: 1$ complex into a $1: 2$ one. To ascertain this information, we measured the heats of mixing of Poly A and Poly $U$ in the ratio of $1: 2$ under the same experimental conditions by using the microcalorimeter at $298 \mathrm{~K}$. The heat of mixing for the $1: 2$ complex formation of Poly $A$ and Poly $U$ was estimated to be about $-30 \mathrm{~kJ} / \mathrm{bpm}$. This value is not in agreement with that of the $1: 1$ complex formation of Poly A and Poly U.

On the other hand, the results for the $\mathrm{CD}$ spectra of (Poly A+Poly $U$ ) in the salt concentrations of $10^{-3}, 0.1$, and 0.5 molar at $\mathrm{pH} 7.60$ are given in Figure 5, together with that of Poly $(\mathrm{A}+2 \mathrm{U})$, which has the triple stranded helical structure. The CD spectra obtained reasonably correspond to the formation of the double stranded helical structure of the $\operatorname{Poly}(\mathrm{A}+\mathrm{U})$ complex, as pointed out by Brahms. ${ }^{8}$ Therefore, we concluded that the drastic increase of $\Delta H^{\mathrm{M}}$ with increasing salt concentration may be due to the $1: 1$ complex formation in the range of about 0.1- and 0.5-molar salt concentrations. The interaction between the bases of $\operatorname{Poly}(\mathrm{A}+\mathrm{U})$ complex and $\mathrm{Na}^{+}$ion seems to contribute to

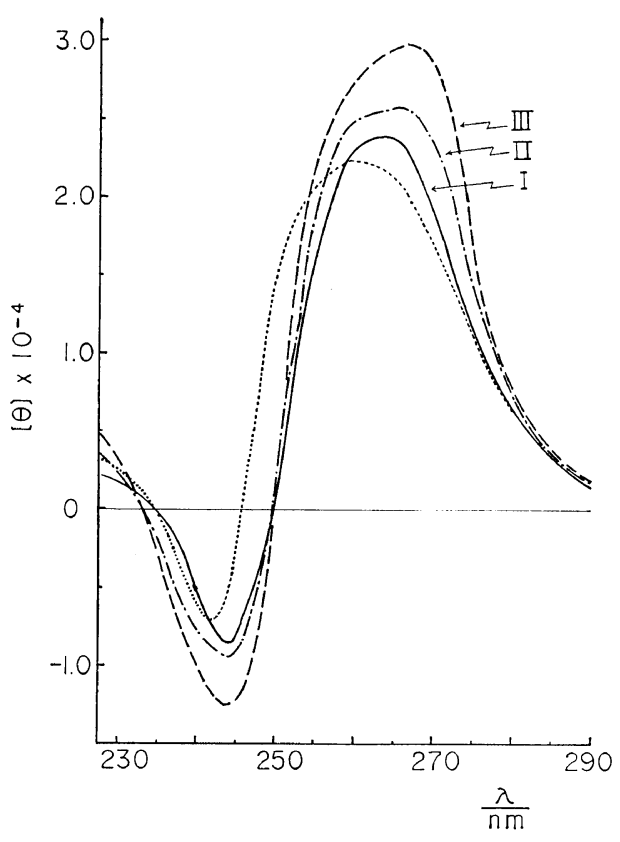

Figure 5. $C D$ spectra for an equimolar mixture of Poly $A$ and Poly $U$ in various $\mathrm{NaCl}$ concentration: I, $10^{-3}$, II, 0.1, and III, 0.5 mole at $\mathrm{pH} 7.60$. ---: $\operatorname{Poly}(\mathrm{A}+2 \mathrm{U})$ in $10^{-3} \mathrm{M} \mathrm{NaCl}$ at $\mathrm{pH} 7.60$.

the strengthening of the thermal stability of the complex, since the positive maximum at $262 \mathrm{~nm}$ for CD spectra of Poly $(A+U)$ in $10^{-3}$ molar salt concentration is shifted to $266 \mathrm{~nm}$ in 0.1 and 0.5 -molar salt concentrations and its intensity becomes slightly larger with increasing salt concentration, as shown in Figure 5 and in Table II, respectively.

$\Delta H^{\mathrm{M}}$ and $\Delta H_{\mathrm{m}}$ of the $1: 1$ complex formation obtained in dilute and high concentrations $(0.1$ molar) of salt are listed in Table III, together with those obtained by other authors. ${ }^{3-6}$ As seen in Table III, the agreement between $\Delta H^{\mathrm{M}}$ estimated from the LKB microcalorimeter and $\Delta H_{\mathrm{m}}$ determined by the DSC method in our present work is fairly close.

In dilute salt concentrations $\left(10^{-5}\right.$ to $10^{-2}$ molar), the effect of a change of $\mathrm{pH}$ on the enthalpy of $\operatorname{Poly}(\mathrm{A}+\mathrm{U})$ is about $-2.6 \mathrm{~kJ} / \mathrm{bpm}$ at $\Delta H^{\mathrm{M}}$ and $3.6 \mathrm{~kJ} / \mathrm{bpm}$ at $\Delta H_{\mathrm{m}}$. Poly $(\mathrm{A}+\mathrm{U})$ complex seems to be formed more readily at $\mathrm{pH} 7.21$ than at 7.60 , since the positive intensity of the CD spectra at $262 \mathrm{~nm}$ at $\mathrm{pH} 7.21$ is 
slightly larger than at $\mathrm{pH} 7.60$, as shown in Table II.

Table II. Maximum wavelength $\left(\lambda_{\max }\right)$ and molecular ellipticity $([\theta])$ of the positive band of CD spectra for an equimolar mixture of Poly $A$ and Poly $U$ in various $\mathrm{NaCl}$ concentrations at $\mathrm{pH} 7.60$ and 7.21

\begin{tabular}{cccccc}
\hline \multirow{2}{*}{$\begin{array}{c}\mathrm{NaCl} \\
\text { concn, } \\
\text { mol } l^{-1}\end{array}$} & \multicolumn{2}{c}{$\mathrm{pH} 7.60$} & & \multicolumn{2}{c}{$\mathrm{pH} 7.21$} \\
\cline { 2 - 3 } \cline { 5 - 6 } & $\lambda, \mathrm{nm}$ & {$[\theta] \times 10^{-4}$} & & $\lambda, \mathrm{nm}$ & {$[\theta] \times 10^{-4}$} \\
\hline $10^{-3}$ & 261.8 & 2.37 & & 262.2 & 2.68 \\
0.1 & 265.7 & 2.56 & & 267.0 & 2.86 \\
0.5 & 266.1 & 2.99 & & 266.5 & 3.26 \\
\hline
\end{tabular}

Table III. Enthalpy formation estimated from heat of mixing and transition enthalpy from the DSC method for the $\operatorname{Poly}(\mathrm{A}+\mathrm{U})$ complex in dilute and $0.1-M \mathrm{NaCl}$ respectively

\begin{tabular}{cccccc}
\hline \multirow{2}{*}{$\mathrm{pH}$} & \multicolumn{2}{c}{$\begin{array}{c}\text { Enthalpy formation } \\
\Delta H^{\mathrm{M}}, \mathrm{kJ}(\mathrm{bpm})^{-1}\end{array}$} & & \multicolumn{2}{c}{$\begin{array}{c}\text { Transition enthalpy } \\
\Delta H_{\mathrm{m}}, \mathrm{kJ}\end{array}$} \\
\cline { 2 - 3 } \cline { 5 - 6 } & dilute & $0.1-M$ & & dilute & $0.1-M$ \\
& $\mathrm{NaCl}$ & $\mathrm{NaCl}$ & & $\mathrm{NaCl}$ & $\mathrm{NaCl}$ \\
\hline 7.60 & -15.5 & -21.0 & & 15.0 & 19.0 \\
7.21 & -18.1 & -22.0 & & 18.6 & 21.0 \\
7.0 & - & $-24.2^{3)}$ & - & $34.3^{6)}$ \\
6.8 & - & $-24.8^{41}$ & - & $35.6^{5)}$ \\
\hline
\end{tabular}

In the case of 0.1-molar salt concentration, $\Delta H^{\mathrm{M}}$ estimated from this study shows a slightly smaller value than that obtained by other authors. ${ }^{3,4}$ It is difficult to determine from our information whether $\Delta H^{\mathrm{M}}$ depends on $\mathrm{pH}$ or not, as seen in Table III. The value of $\Delta H_{\mathrm{m}}$ in the 0.1-molar $\mathrm{NaCl}$ solution from our present work and that from other authors ${ }^{5,6}$ is not in agreement. However, in our present work, the calorimetric results seem to correspond exactly to spectral phenomena, indicating that our result may be rather reliable.

\section{REFERENCES}

1. R. D. Stevens and G. Felsenfeld, Biopolymers, 2, 293 (1964).

2. R. Warner, J. Biol. Chem., 229, 711 (1957).

3. M. A. Rawitscher, P. D. Ross, and J. M. Sturtevant, J. Amer. Chem. Soc., 85, 1915 (1963).

4. P. D. Ross and R. L. Scruggs, Biopolymers, 3, 491 (1965).

5. E. Neumann and Th. Ackerman, J. Phys. Chem., 71, 2377 (1967).

6. H. Krakauer and J. M. Sturtevant, Biopolymers, 6, 491 (1968).

7. Y. Baba and A. Kagemoto, Biopolymers, 13, 339 (1974).

8. J. Brahms, J. Mol. Biol., 11, 785 (1965). 